\title{
A Review of Predictability Studies of Atlantic Sector Climate on Decadal Time Scales
}

\author{
M. LATIF \\ Leibniz-Institut für Meereswissenschaften, Kiel, Germany \\ M. COLLINS \\ Hadley Centre for Climate Prediction and Research, Met Office, Exeter, United Kingdom \\ H. POHLMANN \\ Max-Planck-Institut für Meteorologie, Hamburg, Germany \\ N. KEENLYSIDE \\ Leibniz-Institut für Meereswissenschaften, Kiel, Germany
}

(Manuscript received 6 October 2004, in final form 7 November 2005)

\begin{abstract}
This review paper discusses the physical basis and the potential for decadal climate predictability over the Atlantic and its adjacent land areas. Many observational and modeling studies describe pronounced decadal and multidecadal variability in the Atlantic Ocean. However, it still needs to be quantified to which extent the variations in the ocean drive variations in the atmosphere and over land. In particular, although a clear impact of the Tropics on the midlatitudes has been demonstrated, it is unclear if and how the extratropical atmosphere responds to midlatitudinal sea surface temperature anomalies.

Although the mechanisms behind the decadal to multidecadal variability in the Atlantic sector are still controversial, there is some consensus that some of the longer-term multidecadal variability is driven by variations in the thermohaline circulation. The variations in the North Atlantic thermohaline circulation appear to be predictable one to two decades ahead, as shown by a number of perfect model predictability experiments. The next few decades will be dominated by these multidecadal variations, although the effects of anthropogenic climate change are likely to introduce trends. Some impact of the variations of the thermohaline circulation on the atmosphere has been demonstrated in some studies so that useful decadal predictions with economic benefit may be possible.
\end{abstract}

\section{Introduction}

Over the last 20 years we have seen major developments in seasonal forecasting, and now many centers around the world routinely make seasonal forecasts. The success of these efforts is largely based on the predictability of the El Niño-Southern Oscillation (ENSO) phenomenon, and in our ability to capture it in our models and statistical schemes. Process studies, observations, and simple models have played a central role in

Corresponding author address: Dr. Mojib Latif, Leibniz-Institut für Meereswissenschaften, Duesternbrooker Weg 20, Kiel D-24105, Germany.

E-mail: mlatif@ifm-geomar.de the development of seasonal forecasting and have lead to the design and implementation of the Tropical Ocean Global Atmosphere/Tropical Atmosphere Ocean (TOGA/TAO) observational array (McPhaden et al. 1998), which is crucial in monitoring and prediction.

In contrast to seasonal forecasting, decadal to multidecadal climate predictions are at an infant stage. ${ }^{1}$

\footnotetext{
${ }^{1}$ The term "decadal to multidecadal" is a rather loose definition of time scales usually covering anything from a few years to a few centuries. While this is somewhat inadequate, it pervades the literature and is used liberally in meetings and at conferences. Hence we accept its use in this paper, and when specific studies are quoted, every effort is made to be specific about the time scales and averaging periods used.
} 
Nonetheless, there are many things that can be learned from seasonal forecasting experience. Paramount among these is the recognition that better understanding of the physical mechanisms involved and better monitoring systems are needed for advances to be made. In terms of understanding decadal variability, we are handicapped much more significantly by a lack of adequate data and shall have to wait much longer to get it. Thus, in decadal variability studies there has been a heavy reliance on models. But models do not always agree with each other or with observations and thus, while models have been helpful in identifying possible mechanisms, the true mechanisms for decadal variability are still not known. However in this respect, observations can play a crucial role: They can be used to reduce model uncertainties through improvements in model physics, especially those aspects believed important to decadal and multidecadal time scales, and on which models disagree.

As with seasonal forecasting, decadal to multidecadal climate predictions are of economic, political, and public interest. Their value lies in their relevance to planning the future in all fields that depend on climate to some degree. This includes, for example, the choice of agricultural species, insurance fees, plans of infrastructure, the energy sector, or simply the diameter of gutters. Unlike seasonal forecasting, the relevant periods are longer than a single political reign, and anthropogenic forcing of climate becomes an issue.

Here we review what is known about decadal predictability in the Atlantic sector. This paper is organized as follows. We start in section 2 with a brief description of the global patterns of decadal predictability. In section 3, we describe briefly some observations of the decadal to multidecadal variability in the Atlantic sector. We discuss in section 4 what is known about the mechanisms that lead to climate variability in the Atlantic sector at decadal to multidecadal time scales and in section 5 to which extent this variability can be predicted. Section 6 deals with ensemble prediction techniques. In section 7 the interference of the internal variability with anthropogenic climate change is discussed. The conclusions of this paper are presented in section 8 .

\section{Global pattern of decadal to multidecadal predictability}

In this section we examine the global pattern of decadal predictability as found in potential (diagnostic) and classical (prognostic) predictability studies, which are two common methods for estimating decadal predictability. As outlined by Boer (2004), potential pre- dictability attempts to quantify the fraction of longterm variability that may be distinguished from the internally generated natural variability, which is not predictable on long time scales, and so may be considered "noise" (Hasselmann 1976; Frankignoul et al. 1997). The long-term variability "signal" that rises above this noise, if it exists and is of appreciable magnitude, is deemed to arise from processes operating in the physical system that are assumed to be, at least potentially, predictable. Decadal potential predictability is defined as the ratio of the variance on the decadal time scales to the total variance (Boer 2000).

Classical predictability studies consist of performing ensemble experiments with a single coupled model perturbing only the initial conditions (Griffies and Bryan 1997a,b; Grötzner et al. 1999; Boer 2000; Collins 2002; Collins and Sinha 2003; Pohlmann et al. 2004). In these studies, the predictability of a variable is given by the ratio of the actual signal variance to the ensemble variance. These experiments provide in most cases an upper limit of predictability in the models used since they assume a perfect model and near-perfect initial conditions. Although potential predictability can be estimated from observations, in practice data records are rather short and tend to be less reliable for earlier periods and, hence, it is often estimated from model simulations. Thus, both of these predictability estimates rely heavily on models. A third method exists that is also model based. This method compares the variability simulated with and without the inclusion of active ocean dynamics and identifies those regions in which ocean dynamics are important in generating the variability. It is likely that these regions are also the regions of high predictability potential (Park and Latif 2005).

All three methods, the potential predictability approach (Boer 2001), the classical predictability studies (e.g., Pohlmann et al. 2004), and the ocean dynamics approach (Park and Latif 2005) indicate four regions where predictability may exist at decadal time scales: the North Atlantic, the Southern Ocean, the North Pacific, and the tropical Pacific. These regions are shown to be largely model independent by Boer (2001), where the potential predictability of decadal means of surface air temperature (SAT) from an ensemble of 11 climate models was calculated (Fig. 1). The most prominent regions are the North Atlantic and the Southern Ocean, where more than $50 \%$ of the variance exists in the decadal band. The North Pacific and tropical Pacific also show a significant fraction of variability at decadal time scales. For the North Atlantic and Southern Ocean, the results of the Collins and Sinha (2003) and Pohlmann et al. (2004) classical predictability studies with coupled models are in good agreement with Boer's (2001) study, 


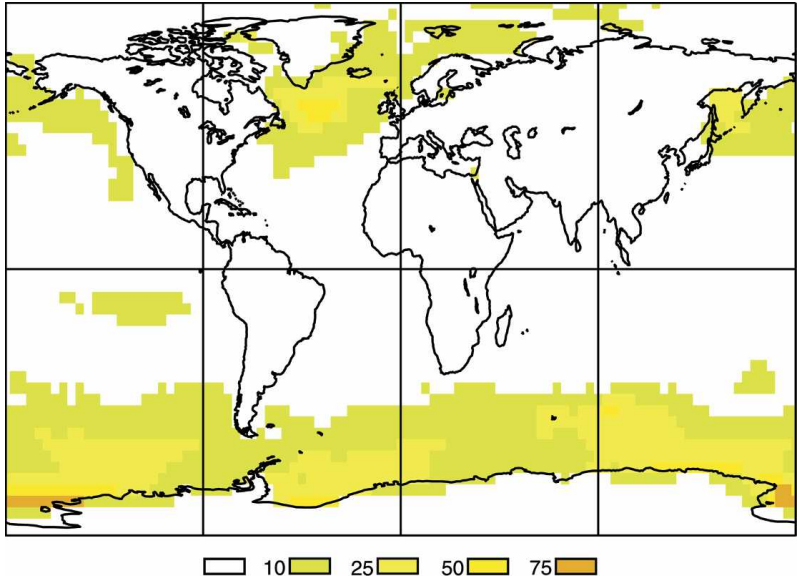

FIG. 1. Map of potential decadal predictability for decadal means as derived from extended-range control integrations with 11 coupled ocean-atmosphere general circulation models. Potential decadal predictability is defined here as the ratio of the decadal variance to the total variance. The North Atlantic Ocean and Southern Ocean stick out as regions of relatively high decadal potential predictability. From Boer (2001)

showing that these regions are predictable out to 10 years or longer.

The North Atlantic has received the largest amount of attention since it shows the largest potential for decadal predictability and because of its potential influence on western Europe and the eastern United States. The Southern Ocean has received the least amount of attention. Hence, the mechanisms for decadal predictability in this region are not yet well understood, and further work is required. In particular, the ocean models need to be improved: At a minimum, the horizontal resolution has to be increased to adequately simulate the variability in the Southern Ocean. However, the multidecadal variability in the Southern Ocean has been shown in observational and coupled model studies to be strongly anticorrelated with that in the North Atlantic (e.g., Latif et al. 2006, and references therein), and the corresponding SST anomaly pattern in the Atlantic is known as the "interhemispheric dipole pattern" (see also below, Fig. 3). Thus, high potential predictability is to be expected, at least at multidecadal time scales, in both the North Atlantic and the Southern Ocean.

The potential predictability found in the North Pacific in Fig. 1 is probably related to the propagation of long baroclinic Rossby waves (e.g., Latif and Barnett 1994; Jacobs et al. 1994; Schneider and Cornuelle 2005). Potential predictability in the tropical Pacific is found off the equator in both hemispheres, but not in the classical ENSO region. Park and Latif (2005) show that ocean dynamics contribute strongly to the decadal vari-

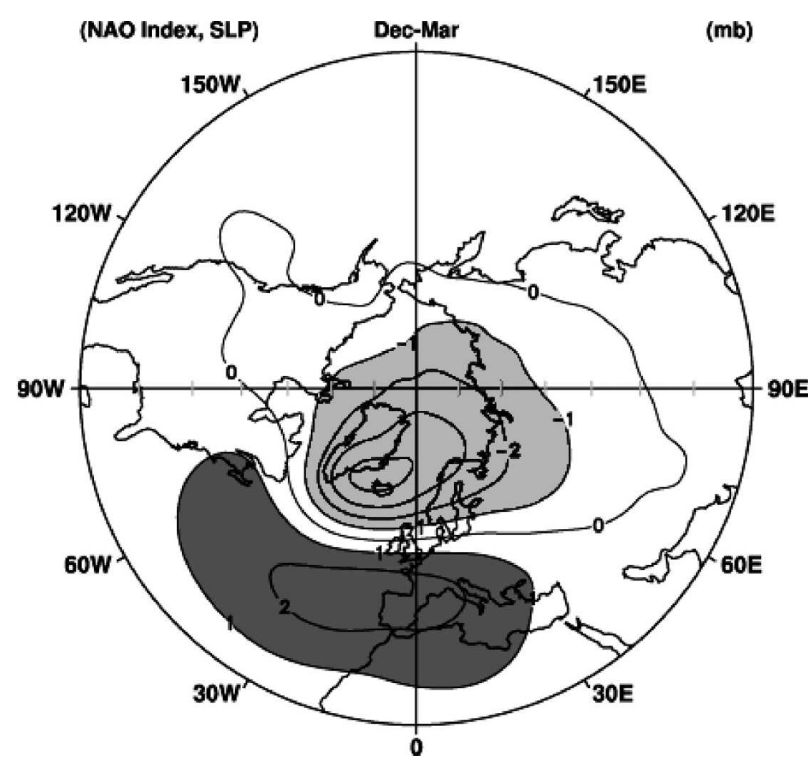

FIG. 2. The pattern of the North Atlantic Oscillation, the leading mode of atmospheric variability over the North Atlantic. Shown is the observed December-March change in sea level pressure (SLP) associated with a one standard deviation change in the NAO index. After Hurrell (1995).

ability in these two regions, but the physical processes behind the decadal variability are not well known. McPhaden and Zhang (2002) and Lohmann and Latif (2005) find some evidence for an active role of the subtropical cells in generating the decadal SST variability off the equator, especially during the so-called mid1970s climate shift.

\section{Observations in the Atlantic sector}

A large number of observational studies exist concerning the decadal to multidecadal variability in the Atlantic sector. Bjerknes (1964), for instance, concluded from his analysis of the observations that the atmosphere drives the ocean at interannual time scales, while at the decadal to multidecadal time scales it is the ocean dynamics that matters. Many subsequent observational and modeling studies agree basically with this view (e.g., Delworth et al. 1993; Latif 1998; and references therein), so the predictability potential in the Atlantic sector is probably largest at the decadal to multidecadal time scales.

The most prominent atmospheric phenomenon over the North Atlantic is the North Atlantic Oscillation (NAO; Hurrell 1995). The NAO is a seesaw in surface pressure, with coherent changes over the high and midlatitudes (Fig. 2). A convenient index of the NAO is the normalized pressure difference between Iceland and 


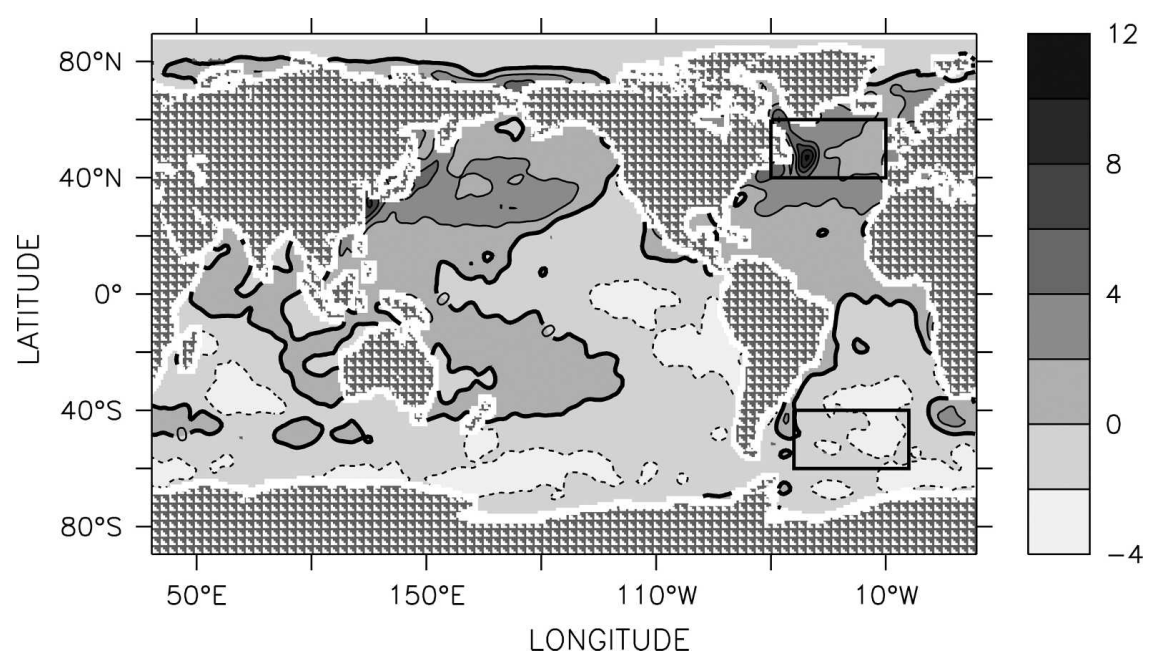

FIG. 3. Linear trend in SST $\left({ }^{\circ} \mathrm{C}\right.$ century $\left.{ }^{-1}\right)$ observed during the period 1980-2004. The global mean trend was removed to highlight the dynamical changes in the presence of global warming. A clear interhemispheric dipole is seen in the Atlantic, which can be used as a fingerprint to detect changes in the MOC. The two boxes indicate the regions used to define the dipole SST anomaly index shown in Fig. 4.

the Azores. The NAO index exhibits rather strong interannual variability, but also some considerable decadal to multidecadal variability (Fig. 4 shows a lowpass filtered version). The variations in the NAO have been clearly linked to surface temperature and precipitation variations over Europe and North America. In particular, the anomalously mild winters over northern and central Europe during the last few decades have been attributed to an intensification of the NAO. It has been shown that decadal to multidecadal variations coherent with those in the NAO can be also observed in the ocean (Curry et al. 1998), which implies the existence of some kind of air-sea interactions. We shall discuss below what is known about the nature of these interactions.

We turn now to the ocean. Folland et al. $(1984,1986)$ describe multidecadal variations in the Atlantic sea surface temperature (SST) and the interhemispheric dipole pattern and link them to West African (Sahelian) rainfall. Deser and Blackmon 1993 investigated the variability of the surface climate over the North Atlantic and described two modes that are relevant here: a quasi-decadal mode and a multidecadal mode. The latter was also described by Kushnir (1994). Mann et al. (1998) analyzed the global-scale temperature patterns during the past six centuries using proxy climate indicators. They identified an interannual to decadal mode in the Atlantic that is associated with the North Atlantic Oscillation. They also identified a multidecadal mode, which resembles the interhemisperic contrast mode in the Atlantic described by Folland et al. (1984, 1986).
As an example of the multidecadal variability, the linear trend in the global SST observed during the period 1980-2004 is displayed in Fig. 3. The global mean trend was removed to highlight the dynamical changes in the presence of global warming. Two features deserve attention: a Pacific SST anomaly pattern resembling the Pacific Decadal Oscillation (PDO) and the dipolar interhemispheric SST anomaly pattern in the Atlantic, with uniform (positive) SST changes over most of the North Atlantic and anomalies of opposite sign in the Southern Hemisphere (see also Latif et al. 2004, 2006; Sutton and Hodson 2005; Knight et al. 2005). This dipolar pattern is associated with a clear multidecadal time scale and is probably connected to the meridional overturning circulation in the Atlantic (MOC), as shown by Latif et al. 2004 analyzing a coupled model simulation. Latif et al. (2005) show that the variations in the MOC, as expressed by a dipolar SST anomaly (SSTA) index, are driven by the lowfrequency variations in the NAO and lag them by about a decade (Fig. 4). The changes in the NAO drive changes in the Labrador Sea convection, as expressed by the depth of the Labrador seawater (LSW) (Fig. 4), and these drive in turn the changes in the MOC. This statistical relationship between NAO, LSW, MOC, and SST is important in light of decadal MOC/SST predictability in the Atlantic, as the state of the multidecadal mode in the Atlantic may be predictable from the history of the NAO. Although it is relatively well accepted that the atmospheric response to the ocean variability is strongest on decadal to multidecadal time scales, it is not clear to what extent the NAO-induced 

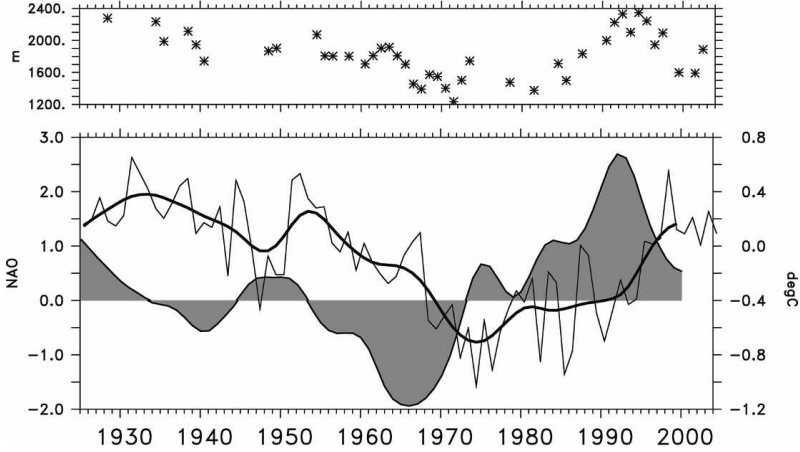

FIG. 4. Time series of the winter [December-March (DJFM)] NAO index (shaded curve), a measure of the strength of the westerlies and heat fluxes over the North Atlantic, and the Atlantic dipole SST anomaly index $\left({ }^{\circ} \mathrm{C}\right.$, black curve), a measure of the strength of the MOC. The NAO index is smoothed with an 11-yr running mean and the dipole index is unsmoothed (thin line) and smoothed with an 11-yr running mean filter (thick line). Multidecadal changes of the MOC as indicated by the dipole index lag those of the NAO by about a decade, supporting the notion that a significant fraction of the low-frequency variability of the MOC is driven by that of the NAO. (top) Annual data of LSW thickness (m), a measure of convection in the Labrador Sea, at Ocean Weather Station Bravo, defined between isopycnals $\sigma_{1.5}=34.72$ 34.62 following Curry et al. (1998).

multidecadal changes in the MOC and SST will feed back onto the NAO itself.

The SSTA signature of the multidecadal mode is distinct from the well-known North Atlantic SSTA tripole pattern (Visbeck et al. 1998), which is the leading mode on interannual to decadal time scales. The SSTA tripole can be basically understood as the ocean's mixed layer response to anomalous heat flux forcing associated with the NAO. In addition to the modes already discussed, a tropical Atlantic dipole has been described by Chang et al. (1997), but it is still controversial whether the dipole can be regarded as a physical mode of the system (e.g., Dommenget and Latif 2002). As shown by Mann et al. (1998), the multidecadal mode existed throughout the last few centuries, so it can be regarded as a stable mode of the Atlantic climate system. In the remaining sections of this paper we concentrate mostly on this multidecadal mode.

\section{Dynamics of the decadal to multidecadal variability}

We turn now to model simulations in order to address the mechanisms underlying the decadal to multidecadal variability and to discuss its predictability. We describe uncoupled simulations with atmosphere and ocean models forced by observed boundary conditions as well as coupled integrations.

\section{a. Ocean-forced atmospheric variability}

The mechanisms by which the extratropical atmosphere responds to midlatitudinal SST anomalies are still highly controversial [see, e.g., the review paper by Kushnir et al. (2002)]. It has been shown, however, that strong changes in the extratropical ocean can exert a significant influence on the atmosphere. The most prominent example is the collapse of the thermohaline circulation in the Atlantic, which can occur with and without external (greenhouse) forcing [see, e.g., the review of Manabe and Stouffer (1999, and references therein) describing results of the Geophysical Fluid Dynamics Laboratory (GFDL) R15 coupled model and Vellinga and Wood (2002)].

Ensembles of uncoupled atmosphere general circulation model (AGCM) experiments forced by the observed history of SSTs and sea ice distributions are used to identify atmospheric predictability under the assumption that the boundary conditions are themselves predictable. Different AGCMs simulate successfully part of the atmospheric decadal variability in the North Atlantic sector (e.g., Rodwell et al. 1999; Mehta et al. 2000; Latif et al. 2000), which indicates some ocean control on the atmosphere. However, it remains controversial which parts of the World Ocean drive the low-frequency variations in the atmosphere, specifically in the NAO. While Rodwell et al. (1999), for instance, argue that it is mainly the North Atlantic SST, some more recent studies indicate a strong impact of the Tropics, specifically the Indo-Pacific region, on the NAO at decadal to multidecadal time scales (e.g., Hoerling et al. 2001; Bader and Latif 2003). Bader and Latif show explicitly that it is the Indian Ocean that had a quite strong impact on the NAO during the last 40 years. The strength of the NAO response in the AGCM-forced experiments, however, underestimates the observed trend. Tropical Pacific SSTs influence both the tropical Atlantic region and the extratropical Atlantic climate. It has been shown by Fraedrich and Müller (1992), analyzing observations, and by Merkel and Latif (2002), conducting AGCM integrations, that there is a significant response of the atmosphere over the North Atlantic region to ENSO-related variations in tropical Pacific SST.

Potential predictability is estimated from forced AGCM experiments by comparing external (ocean) forced and total climate variance (e.g., Rowell 1998). Although these studies have been criticized, since they exclude any feedback of the atmosphere on the ocean (Barsugli and Battisti 1998; Bretherton and Battisti 2000), they provide a first estimate of how much of the atmospheric variability may be predictable. Rowell and 
Zwiers (1999) indicate that the Tropics are generally more predictable than the extratropics. These results were further quantified in the Mechanisms and Predictability of Decadal Fluctuations in Atlantic-European Climate (PREDICATE) project (Sutton et al. 2003), where the potential predictability of the North Atlantic-European region derived from four AGCMs forced by observed SST and sea ice distributions was systematically compared. The results showed that potential decadal predictability is highest in the summer season both for tropical and extratropical parts of the North Atlantic-European region. In summer (winter), roughly $60 \%(50 \%)$ and $30 \%(20 \%)$ of the variance is potentially predictable for the tropical and extratropical parts of the North Atlantic-European region, respectively. There are, however, significant differences between estimates of potential predictability from different atmosphere models, particularly in spring and autumn.

In the PREDICATE project, experiments were also carried out with different AGCMs forced by idealized patterns of Atlantic SST anomalies (Rodwell et al. 2004). The SST anomalies were identified from observations using a lagged maximum covariance analysis as those most likely induce a significant response. A key finding was that, contrary to expectations, the response to the SST forcing was very consistent among the different atmosphere models. In many cases, the uncertainty was significantly less than the signal strength. The magnitude of the response was generally smaller than the interannual variability but sufficient to be of clear importance for understanding and predicting decadal variability. Similar conclusions were reached by Paeth et al. (2003) analyzing an ensemble of multidecadal AGCM integrations with observed SSTs.

Sutton and Hodson (2003) studied the influence of the ocean on atmospheric variability in the North Atlantic region by applying an optimal detection method to ensemble simulations of an AGCM forced by observed SST. They found that SST variability had a significant influence on the climate of the North Atlantic region during the period 1871-1999. Furthermore, SST variability influenced both interannual variations and longer time scale, multidecadal, variations of North

FIG. 5. Signal-to-noise maximizing analysis of an ensemble of AGCM integrations with observed SSTs. Shown is the mode that reflects the multidecadal modulation of the North Atlantic Oscillation: (a) SLP pattern, (b) time series, and (c) SST pattern. This result indicates that there may be some significant feedback from both the Atlantic and Indian Ocean SSTs to the atmosphere. From Sutton and Hodson (2003). (a) DJF LP Mode 1

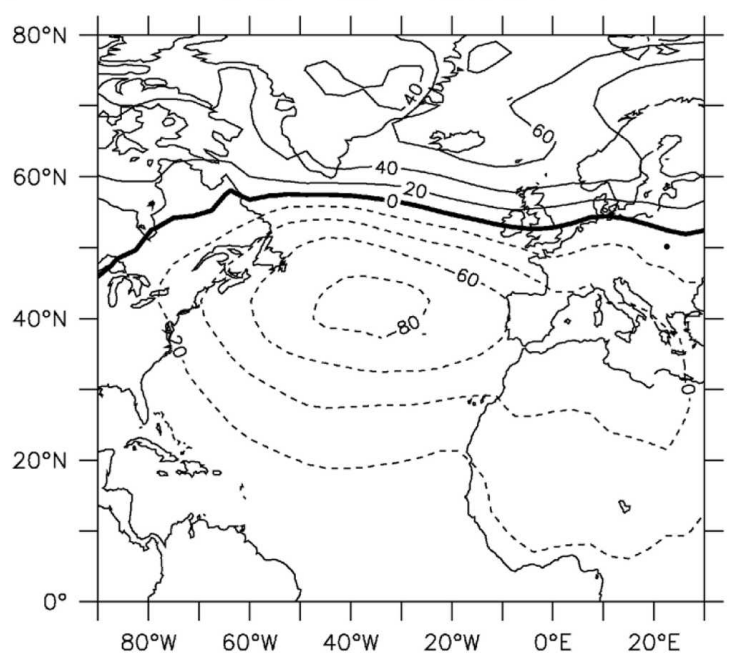

(b)

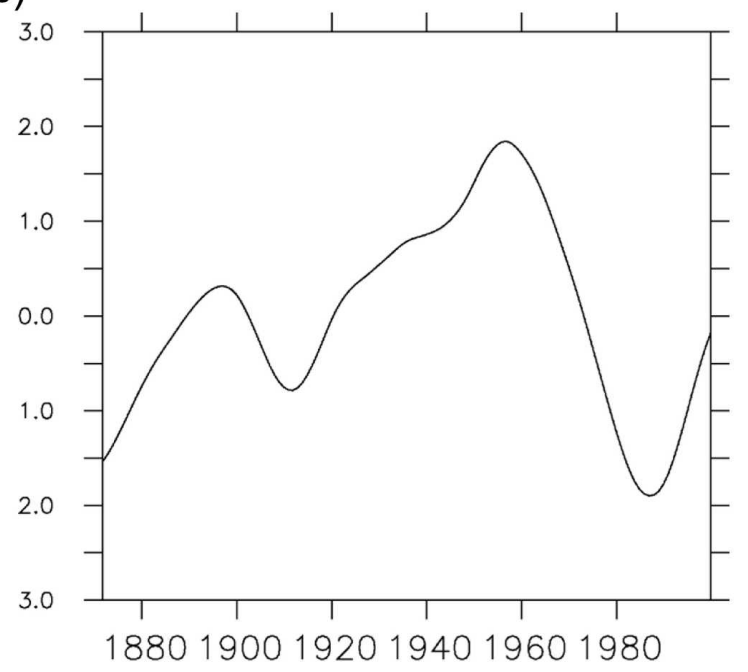

(c)

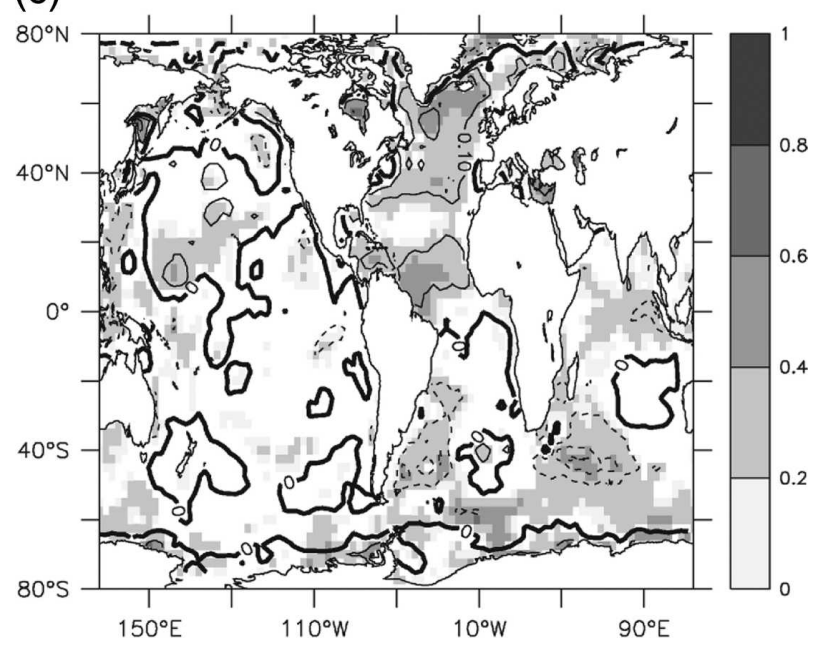



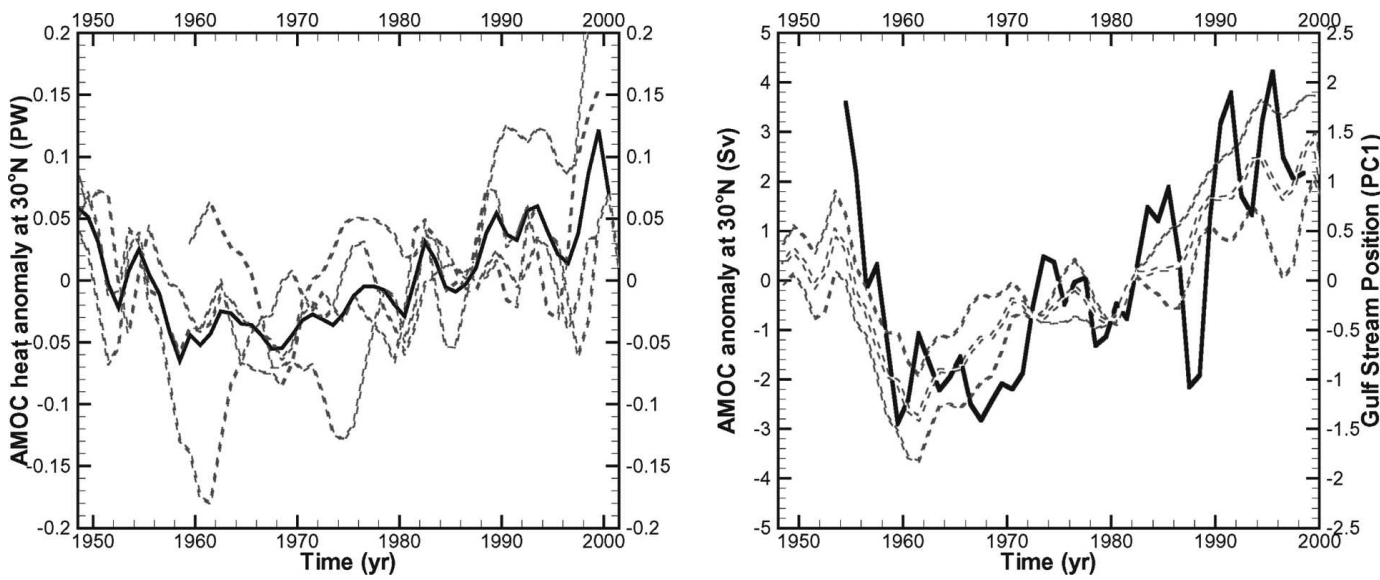

FIG. 6. A North Atlantic overturning index simulated by several OGCMs forced by NCEP reanalyses. (left) The individual simulations (dashed) and the ensemble mean (solid). (right) The ensemble means of the two models that were run in ensemble mode and their mean (dashed), and a Gulf Stream index (solid) used to monitor the changes in the large-scale circulation of the North Atlantic. From Sutton et al. (2003).

Atlantic climate. An example from this study is shown in Fig. 5, which depicts the multidecadal modulation of the North Atlantic surface pressure by the multidecadal SST variations. The time scale of this mode is clearly multidecadal (Fig. 5b) and the associated sea level pressure anomaly pattern resembles somewhat the NAO (Fig. 5a). The associated SST anomaly is that of the interhemispheric contrast mode in the Atlantic, but strong SST anomalies are seen also in the Indian Ocean. In a more recent study Sutton and Hodson (2005) present evidence that basin-scale changes in the Atlantic Ocean have been an important driver of multidecadal variations in the summertime climate over both North America and western Europe.

In summary, while the mechanisms for the midlatitude response to SST anomalies, particularly the local ones, remains controversial, there is a growing body of studies that show midlatitude atmospheric variability is partly forced by SST anomalies, both locally and remotely. This impact is stronger at decadal to interdecadal relative to the interannual time scales, which is important in view of decadal predictability. However, more work is required to quantify the predictable part of the midlatitude response and to better understand the mechanisms. Thus, in order to exploit the full decadal predictability potential in the Atlantic sector, a global approach is required that considers forcings from both the Tropics and the extratropics. It should be mentioned, however, that tropical decadal SST variability, specifically ENSO-like decadal variability in the Pacific or decadal variations in the Indian Ocean, appears to be less predictable than decadal fluctuations in the North Atlantic (see Fig. 1).

\section{b. Atmosphere-forced oceanic variability}

The complementary problem was studied with different ocean general circulation models (OGCMs) forced by observed atmospheric boundary conditions. Most of these studies were performed by driving the OGCMs with reanalysis products. An example is given from the PREDICATE project (Sutton et al. 2003) in Fig. 6, which shows the strength of the MOC at $30^{\circ} \mathrm{N}$ in an ensemble of five model simulations with identical [National Centers for Environmental Prediction (NCEP) reanalysis] forcing. Some of the model simulations were performed in ensemble mode by varying the initial conditions, but only their ensemble means are shown in Fig. 6a. All models were integrated in a spinup phase with climatological forcing, and the residual drift is much smaller than the variability.

Although the differences between the models are not small, some common features can be seen, for example, a tendency for a reduced strength of the MOC until 1960 and slow increase thereafter (Fig. 6a), which is consistent with the study of Latif et al. (2006) who estimated the multidecadal variability of the MOC from SST observations (Fig. 4). The two models that were run in ensemble mode are shown in terms of their ensemble means in Fig. 6b together with the Gulf Stream index of Joyce et al. (2000) as used by Frankignoul et al. (2001). The latter index is constructed from XBT data at $200 \mathrm{~m}$ during 1954-98 and represents observed temperature anomalies along the mean Gulf Stream path. Since the variability of the MOC is not well known 
from observations, indices like the Gulf Stream index may be taken as a proxy for the large-scale variability of the North Atlantic Ocean. It follows from Fig. 6b that the ensemble means of the two models broadly agree with the Gulf Stream index at the multidecadal time scale, yielding confidence in the simulated variability at these long time scales.

\section{c. Coupled model variability: Internally generated variability}

We turn now to the coupled model studies. Many of the proposed mechanisms for the decadal to multidecadal variability were derived from multicentury-long coupled model simulations and some of them are summarized in the review paper of Latif (1998). As a cautionary note we would like to point out that most studies were conducted with rather coarse resolution models, so it remains to be shown that the physical mechanisms acting in these models are those that operate in high-resolution models and in reality.

There are two leading mechanisms for North Atlantic variability. A first idea is that multidecadal MOC variability is driven by the low-frequency portion of the spectrum of atmospheric flux forcing. Delworth and Greatbatch (2000), investigating the multidecadal variability in the coupled model simulation of Delworth et al. (1993) with the GFDL R15 coupled GCM (CGCM), found such a mode in their analysis of a series of coupled and uncoupled OGCM integrations. The multidecadal variability simulated in the GFDL R15 CGCM discussed in Delworth et al. (1993) involves interactions of the gyre and thermohaline circulations in which the anomalous salt advection into the sinking region plays a crucial role in determining deep convection. Delworth and Greatbatch (2000) show that the multidecadal MOC fluctuations are driven by a spatial pattern of surface heat flux variations that bear a strong resemblance to the NAO. No conclusive evidence is found that the MOC variability is part of a dynamically coupled atmosphere-ocean mode. The study of Saravanan et al. (2000) with an idealized model (with ocean-atmosphere coupling in an Atlantic-like basin) agrees with this first idea. Saravanan et al. further conclude that midlatitude atmospheric predictability is modest compared to the predictability associated with tropical phenomena, like El Niño, and that this predictability arises only from the atmospheric response to oceanic modes of variability, rather than from coupled modes.

A second idea is that the variability is part of a thermohaline-driven coupled atmosphere-ocean mode. Timmermann et al. (1998) found such a mode of vari- ability, with a 35-yr period, in a multicentury integration of the ECHAM3/large-scale geostrophic (LSG) climate model. In their study, an anomalously strong MOC drives positive SST anomalies. The atmospheric response to these SST anomalies involves a strengthened NAO, which leads to anomalously weak evaporation and Ekman transport off Newfoundland and in the Greenland Sea and the generation of negative sea surface salinity (SSS) anomalies. These negative SSS anomalies weaken the deep convection in the oceanic sinking regions and subsequently the strength of the MOC leads to a reduced oceanic poleward heat transport and the formation of negative SST anomalies, which completes the phase reversal. The conflict between these two viewpoints arises because of the uncertainties in the atmospheric response to midlatitude SST anomalies. Thus, in the absence of long observational records, one strategy to identify the role of coupled interactions is to understand the structure and strength of the atmospheric response to midlatitude ocean variability. Whether decadal MOC variability is truly coupled or not, the close correspondence between the North Atlantic SST and MOC variability in conjunction with the dynamical inertia of the MOC should allow for the prediction of the slowly varying component of the North Atlantic climate system (Latif et al. 2004).

There is another important point associated with the dynamical inertia of the MOC relevant for climate change detection: This inertia implies that anthropogenically forced changes in MOC strength (and Atlantic SST) may be masked for several decades by natural multidecadal variability. This is clearly illustrated in greenhouse simulations with the ECHAM5/Max Planck Institute Ocean Model (MPI-OM) coupled model. In Fig. 7, four different greenhouse gas simulations (with a $\mathrm{CO}_{2}$ increase of $1 \%$ per year) initialized from different states of a control integration are shown. While the global mean surface temperature exhibits a rather monotonic increase and virtually no sensitivity to the initial conditions (Fig. 7, left), MOC evolution closely follows that of the control run for some decades (Fig. 7, right). Thus, the MOC in this particular coupled model exhibits a rather strong sensitivity to the initial conditions, which is important in light of decadal predictability and climate change detection. It should be noted, however, that the ECHAM5/MPI-OM coupled model may somewhat overestimate the strength of the multidecadal variability.

\section{d. Coupled model variability: The role of external forcing}

The studies described above indicate a significant role for internally generated decadal variability, but to 

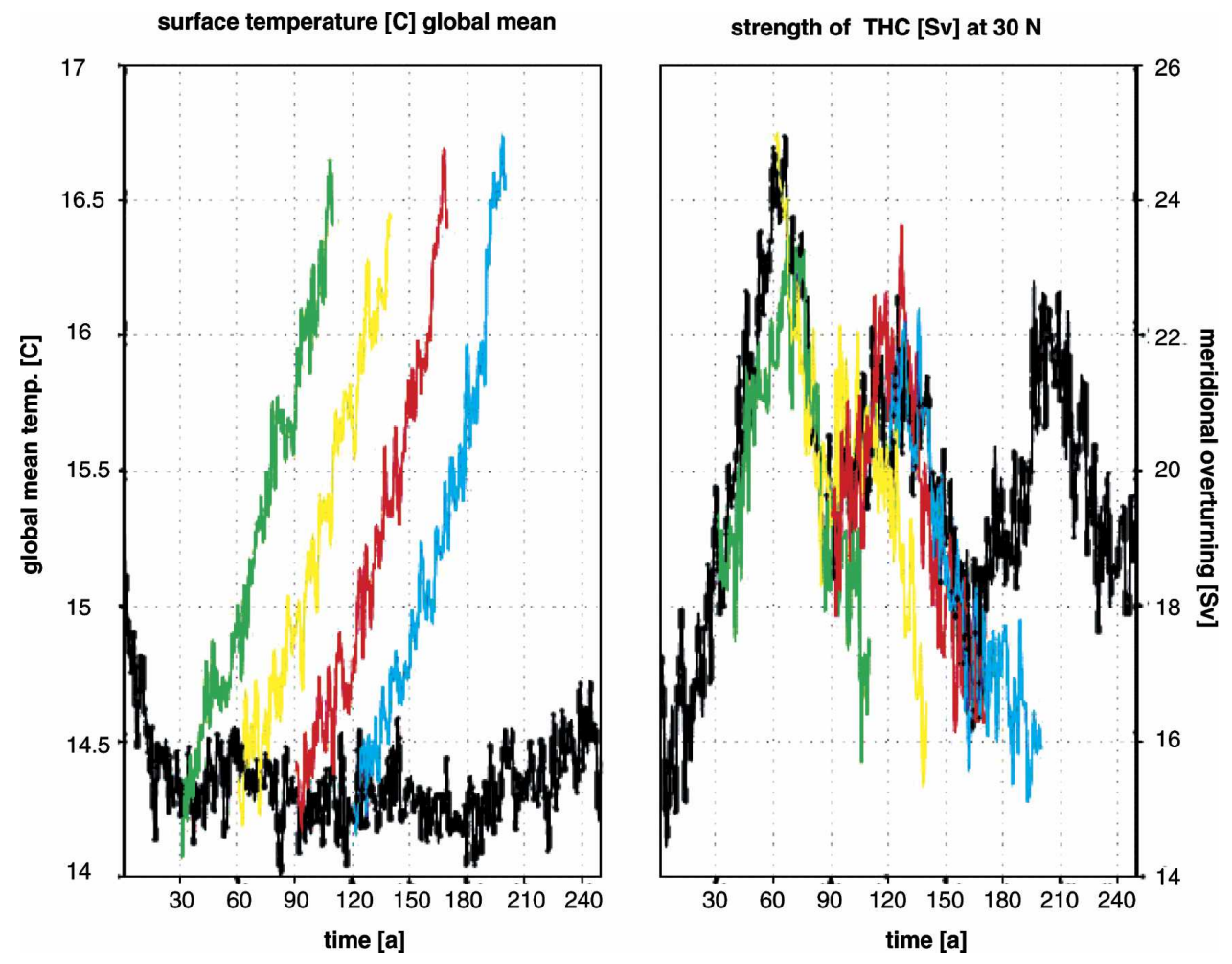

FIG. 7. An ensemble of $1 \% \mathrm{CO}_{2}$ integrations (colored lines) with the MPI coupled ocean-atmosphere GCM ECHAM5/MPI-OM initialized at different conditions of the control integration (black line): (left) evolution of globally averaged surface temperature and (right) evolution of a North Atlantic overturning index. This figure demonstrates that global change predictions pose a joint initial/boundary value problem. After Latif et al. (2004).

what extent did external forcing influence the evolution of the climate in the Atlantic sector during the twentieth century? Many climate models were driven in ensemble integrations with observed anthropogenic (greenhouse gas and aerosol concentrations) and natural (solar) forcings for the twentieth century and were able to simulate realistically the observed long-term evolution of globally averaged surface air temperature (e.g., Stott et al. 2000; Meehl et al. 2003). In particular, the observed warming trend and the superimposed multidecadal variability of globally averaged SAT could be reproduced by prescribing observed forcings. The picture changes, however, when regional climate indices over the North Atlantic are analyzed. The time evolution of the observed North Atlantic SST during the twentieth century, for instance, cannot be reproduced in the ensemble integrations with the Third Hadley Centre Coupled Ocean-Atmosphere GCM (HadCM3) climate model (Fig. 8). This indicates that the climate over the North Atlantic was strongly governed by internal variability during the twentieth century and that external forcing played a minor role. This is, however, somewhat in conflict with simulations of the last millennium. Some models show quite some skill in reproducing the reconstructed multidecadal to centennial variability in Northern Hemisphere surface temperature when driven with external forcings. In particular, multidecadal to centennial changes in the solar input explain a large part of the variability. (e.g., Bauer et al. 2003). Thus, the relative roles of internally generated and externally forced variability still need to be quantified more precisely.

In summary, modeling studies show

1) that part of midlatitude atmospheric variability is forced by the ocean but the mechanisms, the strength, and structure of the response are far from understood;

2) that the response of the MOC on decadal time scale to atmospheric forcing is less controversial and is forced by NAO variability;

3) that whether coupled interactions play any role in the multidecadal vaiability remains controversial because of 1 ;

4) that external forcing also explains a fraction of the variability, but needs better quantification. 

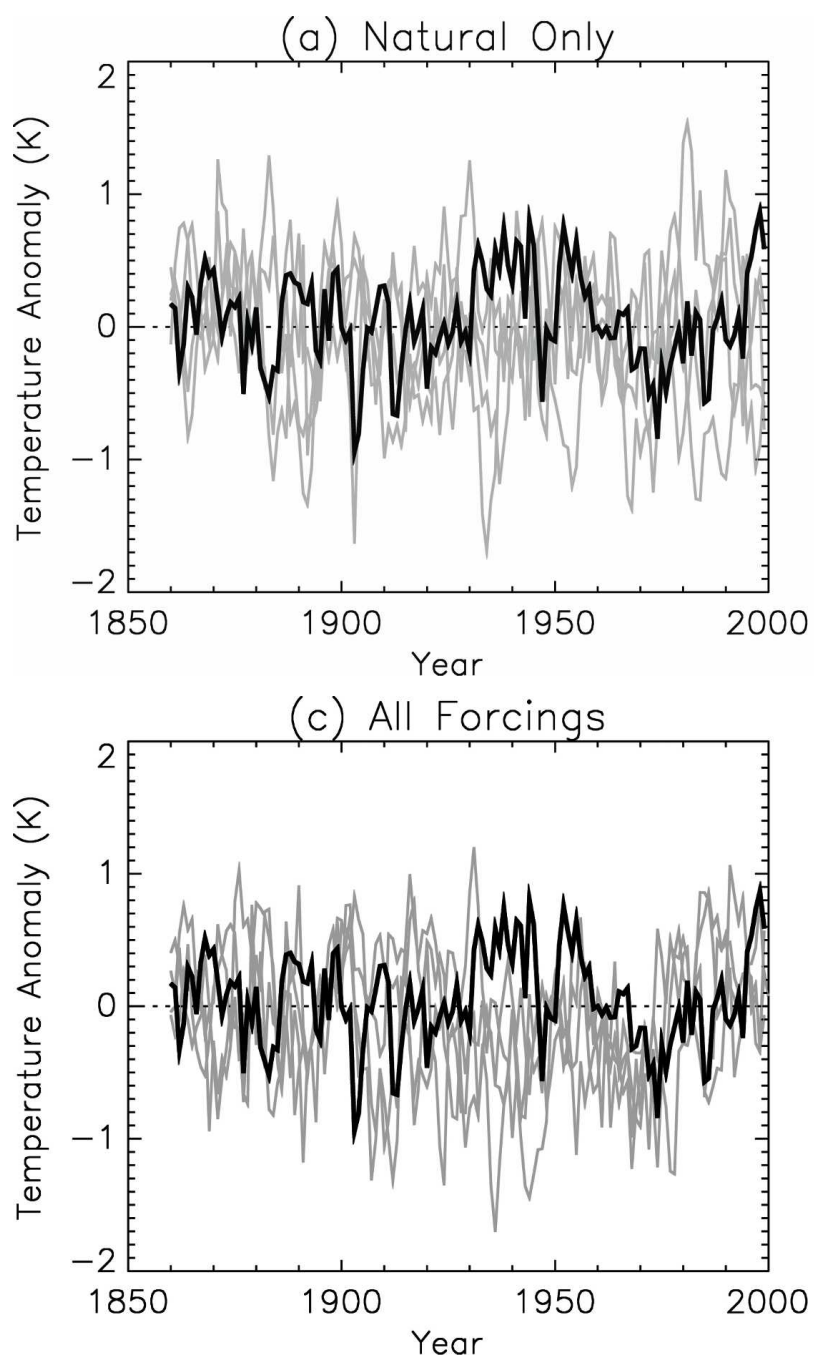

\section{Decadal climate predictability in the North Atlantic-European region}

There were several published classical decadal predictability studies of North Atlantic variability. The early results of Griffies and Bryan (1997a,b) with the GFDL R15 CGCM suggest that variations of North Atlantic SST are predictable at multidecadal time scales. Grötzner et al. (1999) used the ECHAM3/LSG climate model and found that the North Atlantic MOC is predictable about one decade in advance, but North Atlantic SST only about one year. Boer (2000) analyzed simulations with the Canadian Centre for Climate Modelling and Analysis (CCCma) climate model and found that at multidecadal time scales predictability of SAT was mainly restricted to the Southern Ocean. As discussed below, most state-of-the-art climate models seem to indicate that MOC variations are predictable

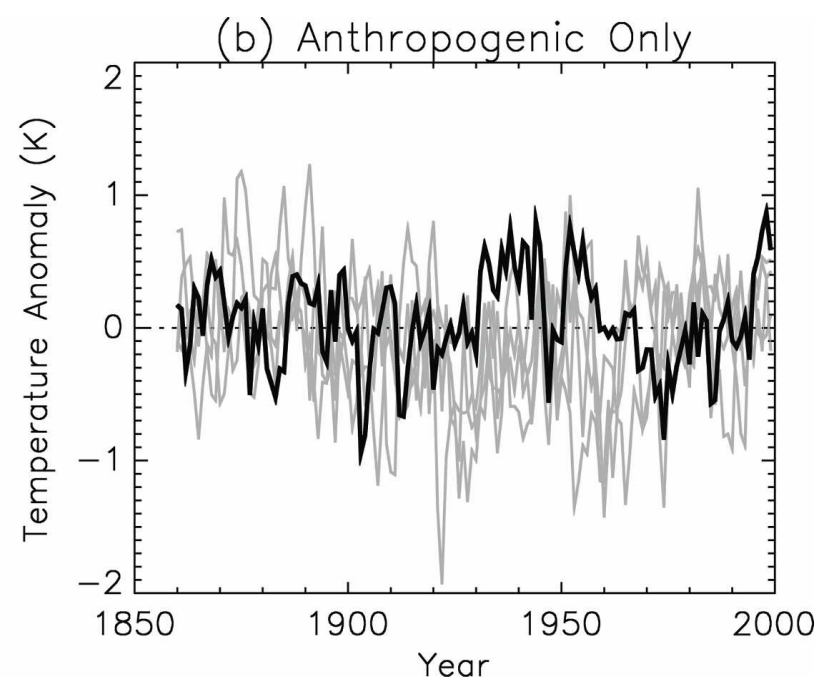

FIG. 8. Simulation of North Atlantic SST (thick black) from 1860 to 2000 in three different ensemble integrations with the Hadley Centre coupled ocean-atmosphere GCM with only natural forcings, with only anthropogenic forcings, and with natural and anthropogenic forcings. The time evolution is not reproduced in the three simulations (thin gray), indicating that the decadal to multidecadal variability in North Atlantic SST is not driven by external forcings but arises basically from internal variability. From M. Collins (2005, personal communication).

out to a decade or more. However, there are major disagreements on the level and extent of predictability of SST and atmospheric quantities, such as SAT and SLP. But there are some positive indications of decadal predictability of SAT and SLP over Europe.

In the PREDICATE project (Sutton et al. 2003) a systematic comparison of the predictability of five state-of-the-art European CGCMs [HadCM3, ECHAM5/MPI-OM, Action de Recherche Petite Echelle Grande Echelle (ARPEGE3/ORCA), Bergen Climate Model (BCM), and ECHAM4/ORCA] was made. The results shown in Fig. 9 represent a synthesis of the coordinated experiments performed with the coupled models. They suggest that both variations in MOC strength and associated surface air temperature variations over the North Atlantic Ocean are potentially predictable a decade or more in advance. A more detailed analysis of skill is given in Collins et al. (2006). 

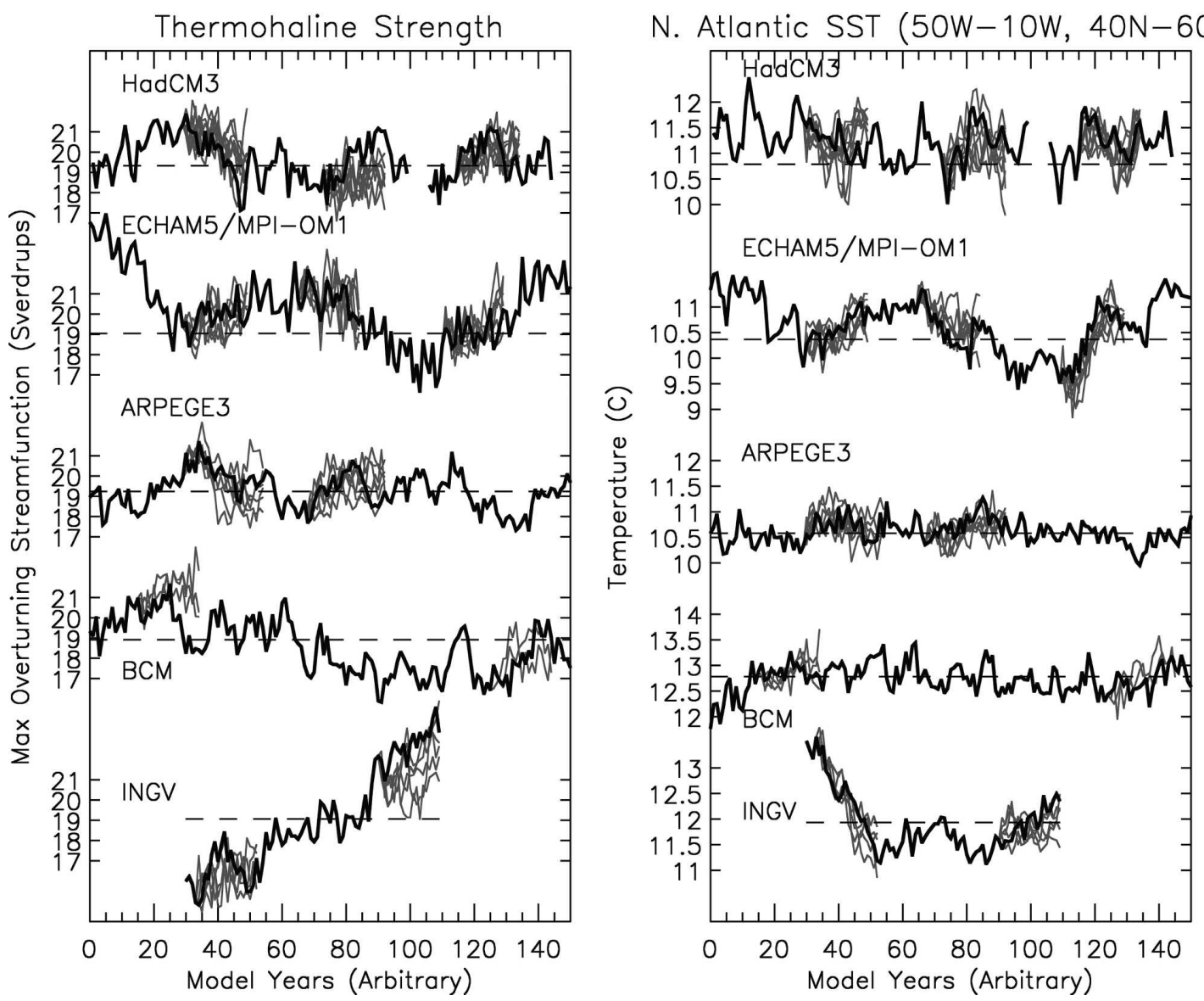

FIG. 9. Classical predictability experiments with five different European coupled ocean-atmosphere GCMs: (left) prediction of thermohaline strength and (right) prediction of North Atlantic SST. The ensemble experiments (thin gray) were initialized from control experiments (thick black) by only perturbing atmospheric initial conditions. The ensemble experiments indicate considerable predictability in the North Atlantic on decadal time scales. From Collins et al. (2006).

For both indicators, predictability measures show significant "skill" over damped persistence, but the SAT indicator is more likely to suffer from contamination from unpredictable weather noise (Collins et al. 2006, their Figs. 3 and 6). The exact level of predictability is dependent on the oceanic initial conditions and on the coupled model used. In addition, there is some suggestion that experiments initiated from stronger than normal MOC states show more potential predictability than those initiated from weaker than average states.

Collins and Sinha (2003), Sutton and Hodson (2005), and Pohlmann et al. (2006) have shown that the multidecadal MOC predictability in the HadCM3 and ECHAM5/MPI-OM models leads to some predictability of European climate. Figure 10 is an example from Pohlmann et al. (2006) and shows the fitted probability density functions (PDFs) of European SAT $\left(35^{\circ}-75^{\circ} \mathrm{N}\right.$, $10^{\circ} \mathrm{W}-40^{\circ} \mathrm{E}$ ) for years in which the maximum MOC anomalies at $30^{\circ} \mathrm{N}$ exceed \pm 0.44 standard deviations (i.e., a third of the years as the data are Gaussian distributed), respectively. In the case of weak MOC conditions the SAT averaged over Europe is colder than in the case of strong MOC conditions. The difference of the mean European SAT for these two cases amounts

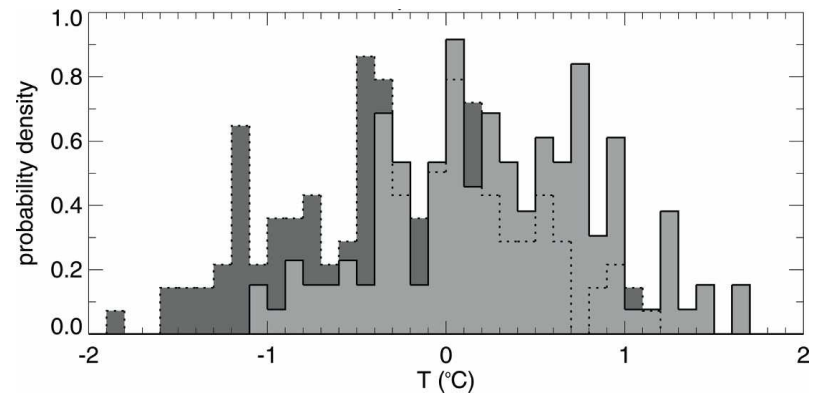

FIG. 10. Fitted PDFs of European SAT for anomalously strong and weak MOC states in the ECHAM5/MPI-OM coupled oceanatmosphere GCM. The two distributions are significantly different at the 95\% level. After Pohlmann et al. (2006). 
to $0.5 \mathrm{~K}$. The two distributions are significantly different at the $95 \%$ level according to a KolmogorovSmirnov and a $t$ test. A probabilistic approach for decadal forecasting over Europe seems therefore promising.

\section{Ensemble prediction}

The value of ensemble prediction is well established in the fields of numerical weather forecasting and seasonal prediction. Ensemble predictions are generally realized by varying the initial conditions. It was shown more recently that multimodel ensembles may be another promising approach for ensemble climate prediction. The Development of a European Multimodel Ensemble System for Seasonal to Interannual Prediction (DEMETER) project (Palmer et al. 2004; http://www. ecmwf.int/research/demeter) addressed the issue of sampling model uncertainty in making seasonal predictions. In this project a multimodel ensemble for seasonal forecasting was constructed and tested: Seven comprehensive coupled ocean-atmosphere models from research centers around Europe were used to make 6-month-long hindcasts over an extended period (of at least $29 \mathrm{yr}$ ). An important outcome of the project is the demonstration of the superiority of the multimodel ensemble over any single model. This feature, although poorly understood, is quite universal and not restricted to any particular region or variable (Palmer et al. 2004). An important outcome from DEMETER is the demonstration that a multimodel ensemble is an effective method for sampling model uncertainties and for making more reliable forecasts, a result that should carry over to decadal-to-multidecadal predictions. As shown in Fig. 1, the different global climate models agree largely on the regions of high decadal predictability potential, which is promising for the development of a multimodel forecasting system for decadal time scales.

\section{Predicting global change}

The reason global change scenarios are discussed here is twofold: First, anthropogenic changes in greenhouse gases/aerosols are an important forcing for climate on longer time scales and thus need to be taken into account when making multidecadal forecasts. Second, natural decadal to multidecadal climate variability can mask anthropogenic climate change, particularly at a regional level (see also Fig. 7). Thus the natural decadal to multidecadal climate variability is an important consideration in predicting anthropogenic climate change.

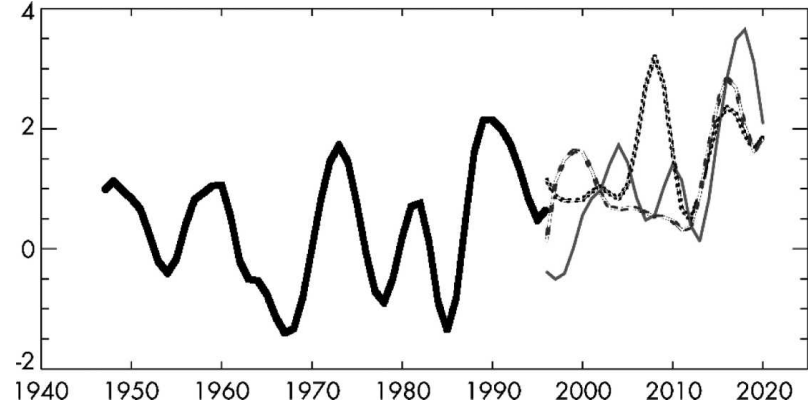

FIG. 11. Northern European SAT during the next 20 years under three different greenhouse warming scenarios as simulated by the Hadley Centre coupled ocean-atmosphere GCM. Apparently, the evolution of Northern European SAT during the next few decades is dominated by the strong internal decadal to multidecadal variability, but some bias toward higher temperatures is introduced by the more abundant greenhouse gases. From R. T. Sutton (2004, personal communication).

The Intergovernmental Panel on Climate Change (IPCC; Houghton et al. 2001) has been established to assess scientific, technical, and socioeconomic information relevant for the understanding of anthropogenic climate change, its potential impacts, and options for adaptation and mitigation. The results of the IPCC report (Houghton et al. 2001) report show a wide range in both projections of atmospheric concentrations of greenhouse gases/aerosols and model dependence of global and local response to the forcing. This is further illustrated in Fig. 11, which shows northern European SAT in three global change simulations. Apparently, the evolution of northern European SAT during the next few decades is dominated by the strong internal decadal to multidecadal variability, but some bias toward higher temperatures is introduced by the more abundant greenhouse gases. The internal decadal variability may be predictable, as outlined above, but the climate change predictions need to be adequately initialized to exploit this predictability. Thus, we are dealing in the future with a joint initial/boundary value problem.

The Atlantic sector may be particularly sensitive to anthropogenic climate change. This is due to the presence of the MOC, which was shown in a number of studies to be sensitive to external forcing. It is likely that strong changes in the strength of the MOC will have direct consequences on North American and European climates. To make projections of future climate, models incorporate past, as well as future, emissions of greenhouse gases and aerosols. Hence, they include estimates of warming to date and the commitment to future warming from past emissions. The globally averaged surface air temperature is projected to increase by $1.4^{\circ}$ to $5.8^{\circ} \mathrm{C}$ (Fig. 12) over the period from 1990 to 2100 


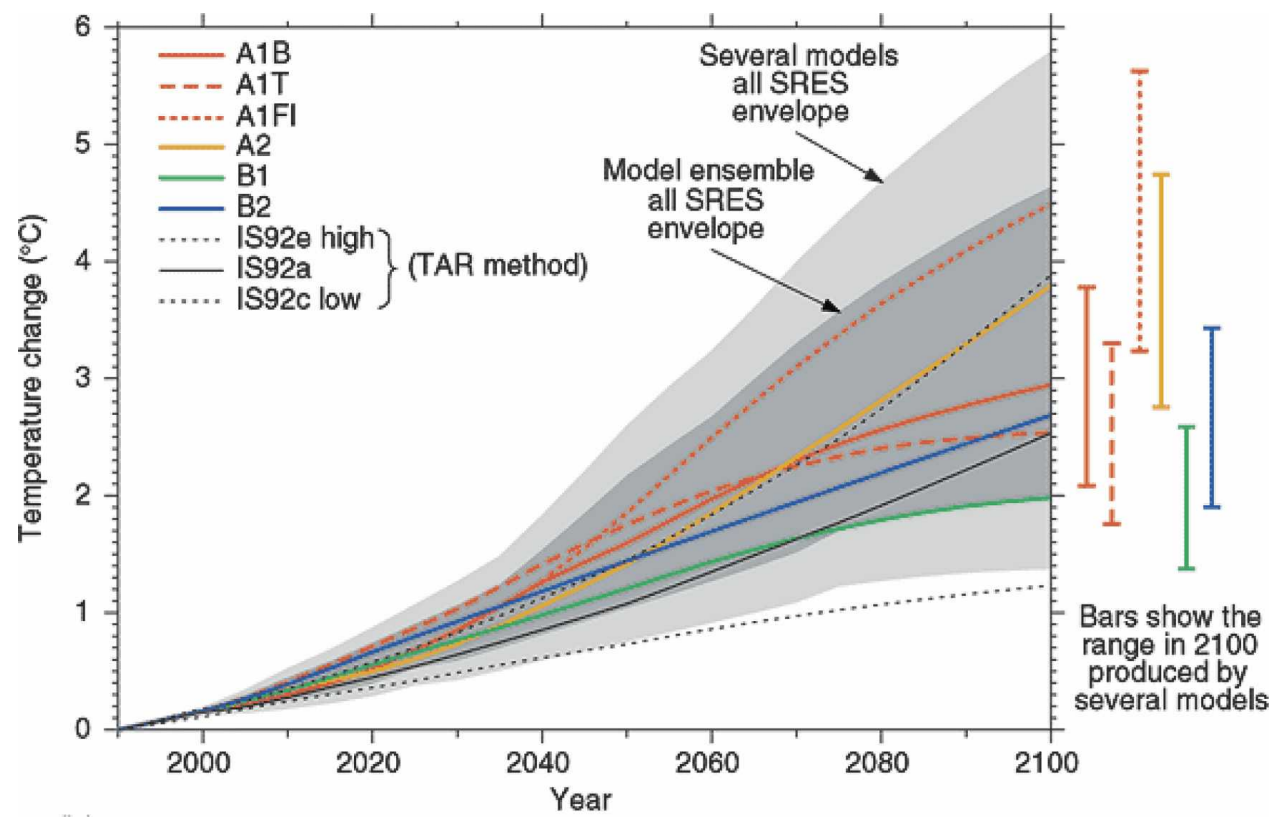

FIG. 12. Evolution of globally averaged SAT for three different scenarios and models. Please note the large spread in the results. From Houghton et al. (2001).

(Houghton et al. 2001). These results are for the full range of Special Report on Emission Scenarios (SRES) scenarios, based on a number of climate models. The projected rate of warming is much larger than the observed changes during the twentieth century and is very likely to be without precedent during at least the last $10000 \mathrm{yr}$, based on paleoclimate data (Houghton et al. 2001). By 2100, the range in the surface temperature response across the group of climate models run with a given scenario is comparable to the range obtained from a single model run with the different SRES scenarios.

A wide range of $\mathrm{MOC}$ behavior is simulated by the ensemble of models collected in the Coupled Model Intercomparison Project (CMIP). Even when the models are forced by the same scenario a rather large spread is observed, indicating a large uncertainty in the response to forcing. Most climate models predict a gradual weakening of the thermohaline circulation in response to global warming under the assumption of some kind of a "business as usual" (BAU) scenario (Fig. 13). This, however, does not lead to a cooling over the North Atlantic or the adjacent land areas (Gregory et al. 2005), but to a local minimum in the warming (Fig. 14). A few models simulate a rather stable MOC (e.g., Latif et al. 2000). The role of the Tropics in stabilizing the MOC through anomalous freshwater fluxes has to be considered in this context. In particular, the anomalous export of freshwater from the Atlantic to the Indo-Pacific region appears to play a crucial role in the stabilization of the MOC. None of the complex climate models simulates some kind of abrupt change in the MOC until 2100 when forced by increased levels of greenhouse gases, as shown by Gregory et al. (2005), analyzing the most recent greenhouse simulations. Thus, it may be concluded that the system is still far beyond a bifurcation point and may be dominated by the multidecadal variability during the next several decades (Latif et al. 2006). This is also supported by a multimillennial control integration with fixed greenhouse gas concentrations, performed with the GFDL R15 climate model, in which regional abrupt climate change is an extremely rare event (e.g., Hall and Stouffer 2001). The role of increased melting from the Greenland ice sheet, however, has to be considered in this context, as it is not included in the climate model simulations.

\section{Summary}

The climate in the Atlantic sector exhibits strong decadal to multidecadal variability. Part of this variability appears to be potentially predictable, especially the part that is related to variations of the thermohaline circulation. The variations of the MOC may be predictable a few decades ahead, as shown by a number of coupled model studies. There is consensus that some of the decadal to multidecadal variability is consistent with Hasselmann's (1976) stochastic climate model scenario and that some part of the variability of the ther- 


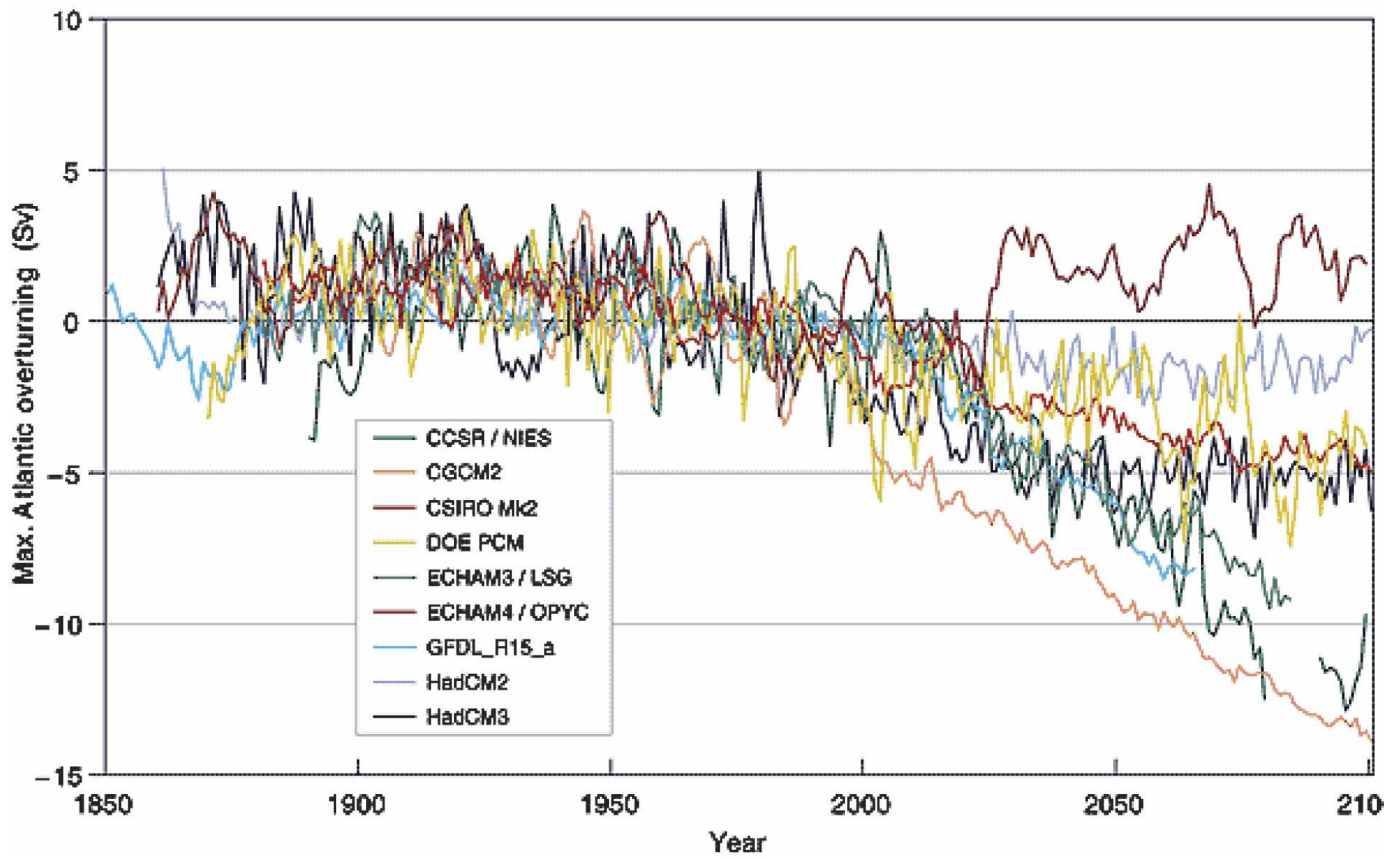

FIG. 13. Evolution of the North Atlantic thermohaline circulation in greenhouse warming simulations with different coupled ocean-atmosphere GCMs. All models were driven with a BAU-type scenario. From Houghton et al. (2001).

mohaline circulation is driven by stochastic variability in the surface heat and freshwater fluxes and, to a lesser extent, wind stress. There is consensus that variability in the MOC will drive some but certainly not all SST variability, but the amount of SST variance explained by MOC variability is large enough to be of societal interest. There is no consensus on the extent, size, and character of the atmospheric response to this SST vari-

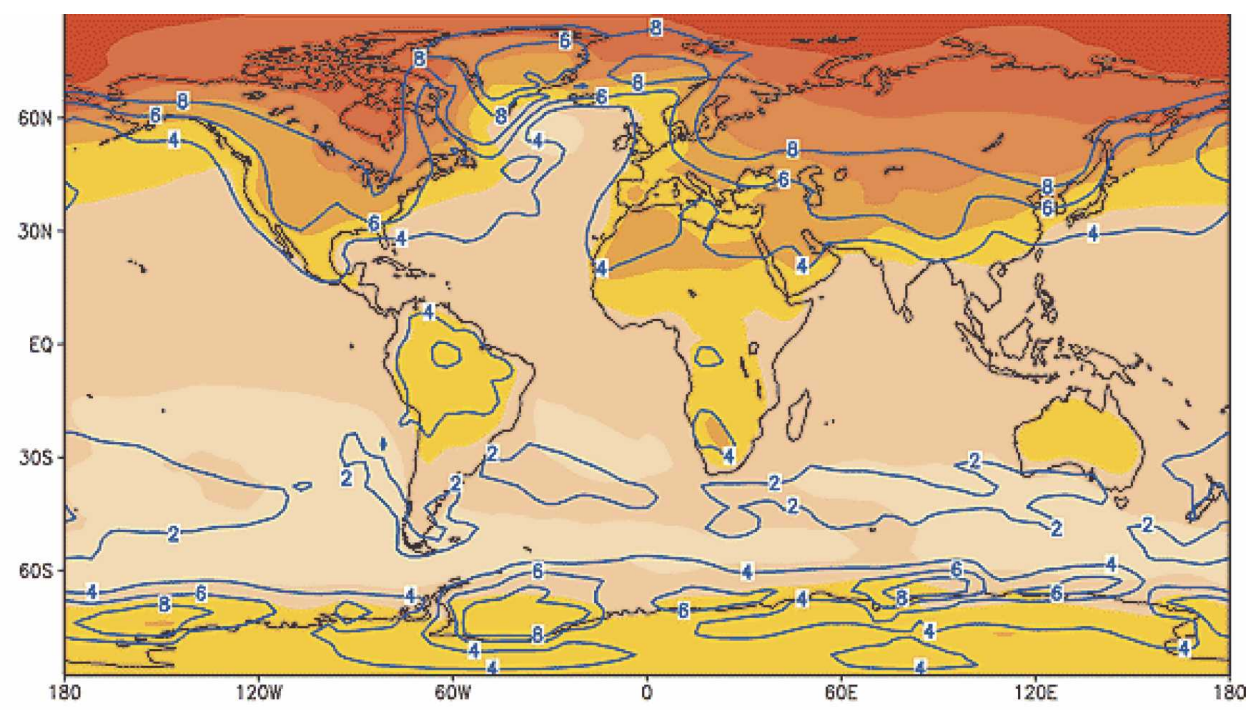

A2

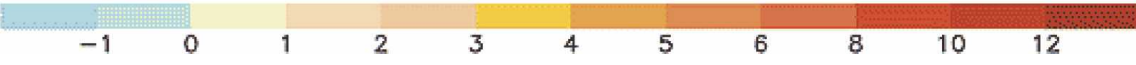

FIG. 14. Multimodel projection of SAT for the year 2100 and scenario A2. Note the minimum of the warming in the North Atlantic, which is forced by a weakening of the North Atlantic thermohaline circulation. From Houghton et al. (2001). 
ability or the extent to which these atmospheric changes subsequently influence the MOC.

A detailed understanding of the true mechanisms for decadal variability is important with respect to developing decadal prediction systems. But the lack of data and the long time scales involved makes this a challenge. There is, however, some recent evidence from observations of the last century and from forced ocean model simulations that the low-frequency variations of the NAO force a lagged response of the thermohaline circulation, which in turn drives a characteristic basinwide Atlantic diplolar SST anomaly pattern (Latif et al. 2006 , and references therein). The lag is of the order of a decade, so the future state of the MOC may be predictable simply from past variations of the NAO. This relationship, however, still needs to be confirmed by much longer (paleoclimatic) records.

Although there is consensus that predictability at decadal time scales exists in the Atlantic Ocean, the extent of predictability in the atmosphere, especially over land, is still controversial. It is also uncertain whether the strength of the atmospheric response relative to internal atmospheric variability is significant enough to be of practical use. Most of the effort in understanding these issues has focused on the North Atlantic-European region. The more recent studies would tend to indicate that the climate of Europe does, indeed, exhibit useful decadal predictability (Sutton et al. 2003; Collins and Sinha 2003; Pohlmann et al. 2004, 2006; Sutton and Hodson 2005): Although predictability in decadal mean surface air temperature is mostly restricted to ocean regions, the probability density functions of surface temperature over land (e.g., Europe) are shown to be affected significantly in some models by the decadal to multidecadal variability of the thermohaline circulation. Furthermore, results from ensembles of AGCM experiments forced by observed SST also suggest reasonable agreement between atmospheric model responses (Rodwell et al. 2004).

Until the end of this century, climate models predict that anthropogenic climate change will become more and more important. How precisely global and regional climate will evolve, however, is highly uncertain. The strong internal decadal to multidecadal variability in the Atlantic is likely to mask the anthropogenic climate signal during the next few decades there. Likewise the regional climate of the Atlantic sector during the twentieth century was, in contrast to global climate, dominated by the internal variability. Global warming will, however, introduce a warm bias on the multidecadal time scale. Projections of the strength of this warming depend on the selected scenario and the selected climate model. The warming may well override the am- plitude of the internal decadal to multidecadal variability on the global scale. Regionally, however, changes in the ocean circulation may provide important feedbacks. For the Atlantic sector, the fate of the thermohaline circulation will be important in shaping regional climate change. There exists, however, a large uncertainty concerning the response of the MOC to global warming. Most models predict some weakening of the MOC and a corresponding reduced northward heat transport in the North Atlantic, but the spread in the model results is extremely large. A weakening of the MOC may mediate somewhat the warming over the North Atlantic, but the models still predict considerable warming over land. According to the model simulations, abrupt climate change is not to be expected over the Atlantic sector during the twenty-first century. Instead, the bulk of the climate models simulate rather gradual changes when forced by increased levels of greenhouse gases (Houghton et al. 2001; Gregory et al. 2005).

Thus, some useful decadal predictability of economic value may exist in the Atlantic-European sector. To exploit this decadal predictability, however, a suitable ocean observing system must be installed since the memory of the climate system resides in the Atlantic Ocean. In particular, the thermohaline circulation should be monitored carefully since its variations are most interesting in light of decadal predictability in the Atlantic sector. The current ocean observing system, however, is not suitable to produce ocean analyses that would provide a realistic description of the state of the MOC. A lot of effort should be spent in the next years to implement an "adequate" ocean observing system so that the decadal predictability potential can be exploited. A multimodel approach may be an effective way of sampling model uncertainties. Dealing with the uncertainties of anthropogenic climate forcing seems a bigger problem. But, as 20 years ago people may have wondered if seasonal forecasting would ever be possible, in 20 years from now routine decadal to multidecadal predictions may become accepted.

Acknowledgments. This work was supported by the European Union's PREDICATE, DEMETER, and ENSEMBLES (GOCE-CT-2003-505539) projects.

\section{REFERENCES}

Bader, J., and M. Latif, 2003: The impact of decadal-scale Indian Ocean sea surface temperature anomalies on Sahelian rainfall and the North Atlantic Oscillation. Geophys. Res. Lett., 30, 2169, doi:10.1029/2003GL018426.

Barsugli, J. J., and D. S. Battisti, 1998: The basic effects of atmosphere-ocean coupling on midlatitude variability. J. Atmos. Sci., 55, 477-493. 
Bauer, E., M. Claussen, V. Brovkin, and A. Hünerbein, 2003: Assessing climate forcings of the Earth system for the past millenium. Geophys. Res. Lett., 30, 1276-1279.

Bjerknes, J., 1964: Atlantic air-sea interaction. Advances in Geophysics, Vol. 10, Academic Press, 1-82.

Boer, G. J., 2000: A study of atmosphere-ocean predictability on long time scales. Climate Dyn., 16, 469-472.

— , 2001: Decadal potential predictability in coupled models. CLIVAR Exchanges, Vol. 19, No. 3, International CLIVAR Project Office, Southampton, United Kingdom, 3 pp.

- 2004: Long-timescale potential predictability in an ensemble of coupled climate models. Climate Dyn., 23, 29-44.

Bretherton, C. S., and D. S. Battisti, 2000: An interpretation of the results from atmospheric general circulation models forced by the time history of the observed sea surface temperature distribution. Geophys. Res. Lett., 27, 767-770.

Chang, P., L. Ji, and H. Li, 1997: A decadal climate variation in the tropical Atlantic ocean from thermodynamic air-sea interactions. Nature, 385, 516-518.

Collins, M., 2002: Climate predictability on interannual to decadal time scales: The initial value problem. Climate Dyn., 19, 671692.

- and B. Sinha, 2003: Predictability of decadal variations in the thermohaline circulation and climate. Geophys. Res. Lett., 30, 1306, doi:10.1029/2002GL016504.

_ , and Coauthors, 2006: Interannual to decadal climate predictability in the North Atlantic: A multimodel-ensemble study. J. Climate, 19, 1195-1203.

Curry, R. G., M. S. McCartney, and T. M. Joyce, 1998: Oceanic transport of subpolar climate signals to mid-depth subtropical waters. Nature, 391, 575-577.

Delworth, T. L., and R. J. Greatbatch, 2000: Multidecadal thermohaline circulation variability driven by atmospheric surface flux forcing. J. Climate, 13, 1481-1495.

__ S. Manabe, and R. J. Stouffer, 1993: Interdecadal variations of the thermohaline circulation in a coupled oceanatmosphere model. J. Climate, 6, 1993-2011.

Deser, C., and M. L. Blackmon, 1993: Surface climate variations over the North Atlantic Ocean during winter: 1900-1989. J. Climate, 6, 1743-1753.

Dommenget, D., and M. Latif, 2002: A cautionary note on the interpretation of EOFs. J. Climate, 15, 216-225.

Folland, C. K., D. E. Parker, and F. E. Kates, 1984: Worldwide marine temperature fluctuations 1856-1981. Nature, 310, 670-673.

— T. N. Palmer, and D. E. Parker, 1986: Sahel rainfall and worldwide sea temperatures. Nature, 320, 602-607.

Fraedrich, K., and K. Müller, 1992: Climate anomalies in Europe associated with ENSO extremes. Int. J. Climatol., 12, 25-31.

Frankignoul, C., P. Muller, and E. Zorita, 1997: A simple model of the decadal response of the ocean to stochastic wind forcing. J. Phys. Oceanogr., 27, 1533-1546.

— , G. de Coetlogon, T. M. Joyce, and S. F. Dong, 2001: Gulf Stream variability and ocean-atmosphere interactions. $J$. Phys. Oceanogr., 31, 3516-3529.

Gregory, J. M., and Coauthors, 2005: A model intercomparison of changes in the Atlantic thermohaline circulation in response to increasing atmospheric $\mathrm{CO} 2$ concentration. Geophys. Res. Lett., 32, L12703, doi:10.1029/2005GL023209.

Griffies, S. M., and K. Bryan, 1997a: A predictability study of simulated North Atlantic multidecadal variability. Climate Dyn., 13, 459-488.
- and - 1997b: Predictability of North Atlantic multidecadal climate variability. Science, 275, 181-184.

Grötzner, A., M. Latif, A. Timmermann, and R. Voss, 1999: Interannual to decadal predictability in a coupled oceanatmosphere general circulation model. J. Climate, 12, 26072624.

Hall, A., and R. J. Stouffer, 2001: An abrupt climate event in a coupled ocean-atmosphere simulation without external forcing. Nature, 409, 171-174.

Hasselmann, K., 1976: Stochastic climate models. Part I: Theory. Tellus, 28, 473-485.

Hoerling, M. P., J. W. Hurrell, and T. Y. Xu, 2001: Tropical origins for recent North Atlantic climate change. Science, 292, 90-92.

Houghton, J. T., Y. Ding, D. J. Griggs, M. Noguer, P. J. van der Linden, X. Dai, K. Maskell, and C. A. Johnson, Eds., 2001: Climate Change 2001: The Scientific Basis. Cambridge University Press, $944 \mathrm{pp}$.

Hurrell, J. W., 1995: Decadal trends in the North-AtlanticOscillation regional temperatures and precipitation. Science, 269, 676-679.

Jacobs, G. A., H. E. Hulburt, J. C. Kindle, E. J. Metzger, J. L. Mitchell, W. J. Teague, and A. J. Wallcraft, 1994: Decadescale trans-Pacific propagation and warming effects of an El Nino anomaly. Nature, 370, 360-363.

Joyce, T. M., C. Deser, and M. A. Spall, 2000: The relation between decadal variability of subtropical mode water and the North Atlantic Oscillation. J. Climate, 13, 2550-2569.

Knight, M., R. J. Allan, C. K. Folland, M. Vellinga, and M. E. Mann, 2005: A signature of persistent natural thermohaline circulation cycles in observed climate. Geophys. Res. Lett., 32, L20708, doi:10.1029/2005GL024233.

Kushnir, Y., 1994: Interdecadal variations in the North Atlantic sea temperature and associated atmospheric conditions. $J$. Climate, 7, 141-157.

_- and Coauthors, 2002: Atmospheric GCM response to extratropical SST anomalies: Synthesis and evaluation. J. Climate, 15, 2233-2256.

Latif, M., 1998: Dynamics of interdecadal variability in coupled ocean-atmosphere models. J. Climate, 11, 602-624.

- and T. P. Barnett, 1994: Causes of decadal climate variability over the North Pacific and North America. Science, 266, 634-637.

— K. K. Arpe, and E. Roeckner, 2000: Oceanic control of decadal North Atlantic sea level pressure variability in winter. Geophys. Res. Lett., 27, 727-730.

_ , and Coauthors, 2004: Reconstructing, monitoring, and predicting multidecadal-scale changes in the North Atlantic thermohaline circulation with sea surface temperature. J. Climate, 17, 1605-1614.

— C. Böning, J. Willebrand, A. Biastoch, J. Dengg, N. Keenlyside, G. Madec, and U. Schweckendiek, 2006: Is the thermohaline circulation changing? J. Climate, 19, 4631-4637.

Lohmann, K., and M. Latif, 2005: Tropical Pacific decadal variability and the subtropical-tropical cells. J. Climate, 18, 51635177.

Manabe, S., and R. J. Stouffer, 1999: The role of the thermohaline circulation in climate. Tellus, 51, 91-109.

Mann, M. E., R. S. Bradley, and M. K. Hughes, 1998: Global-scale temperature patterns and climate forcing over the past six centuries. Nature, 392, 779-787.

McPhaden, M. J., and D. Zhang, 2002: Slowdown of the meridi- 
onal overturning circulation in the upper Pacific Ocean. $\mathrm{Na}$ ture, 415, 603-608.

— observing system: A decade of progress. J. Geophys. Res., 103, 14 169-14 240.

Meehl, G. A., W. M. Washington, T. M. L. Wigley, J. M. Arblaster, and A. Dai, 2003: Solar and greenhouse gas forcing and climate response in the twentieth century. J. Climate, 16, 426-444.

Mehta, V. M., M. J. Suarez, J. V. Manganello, and T. L. Delworth, 2000: Oceanic influence on the North Atlantic Oscillation and associated Northern Hemisphere climate variations: 1959-1993. Geophys. Res. Lett., 27, 121-124.

Merkel, U., and M. Latif, 2002: A high-resolution AGCM study of the El Niño impact on the North Atlantic/European sector. Geophys. Res. Lett., 29, 1291, doi:10.1029/2001GL013726.

Paeth, H., M. Latif, and A. Hense, 2003: Global SST influence on twentieth century NAO variability. Climate Dyn., 21, 63-75.

Palmer, T. N., and Coauthors, 2004: Development of a European Multimodel Ensemble System for Seasonal to Interannual Prediction (DEMETER). Bull. Amer. Meteor. Soc., 85, 853872

Park, W., and M. Latif, 2005: Ocean dynamics and the nature of air-sea interactions over the North Atlantic at decadal time scales. J. Climate, 18, 982-995.

Pohlmann, H., M. Botzet, M. Latif, A. Roesch, M. Wild, and P. Tschuck, 2004: Estimating the long-term predictability potential of a coupled AOGCM. J. Climate, 17, 4463-4472.

_- F. Sienz, and M. Latif, 2006: Influence of the multidecadal Atlantic meridional overturning circulation variability on European climate. J. Climate, 19, 6062-6067.

Rodwell, M. J., D. P. Rowell, and C. K. Folland, 1999: Oceanic forcing of the wintertime North Atlantic Oscillation and European climate. Nature, $\mathbf{3 9 8 ,} 320-323$.

—, M. Drevillon, C. Frankignoul, J. W. Hurrell, H. Pohlmann,
M. Stendel, and R. T. Sutton, 2004: North Atlantic forcing of climate and its uncertainty from a multi-model experiment. Quart. J. Roy. Meteor. Soc., 130, 2013-2032.

Rowell, D. P., 1998: Assessing potential seasonal predictability with an ensemble of multidecadal GCM simulations. J. Climate, 11, 109-120.

_ and F. W. Zwiers, 1999: The global distribution of sources of atmospheric decadal variability and mechanisms over the tropical Pacific and southern North America. Climate Dyn., 15, 751-772.

Saravanan, R., G. Danabasoglu, and S. C. Doney, 2000: Decadal variability and predictability in the midlatitude oceanatmosphere system. J. Climate, 13, 1073-1097.

Schneider, N., and B. D. Cornuelle, 2005: The forcing of the Pacific decadal oscillation. J. Climate, 18, 4355-4373.

Stott, P. A., S. F. B. Tett, G. S. Jones, M. R. Allen, J. F. B. Mitchell, and G. J. Jenkins, 2000: External control of 20th century temperature by natural and anthropogenic forcings. Science, 290, 2133-2137.

Sutton, R. T., and D. L. R. Hodson, 2003: Influence of the ocean on North Atlantic climate variability 1871-1999. J. Climate, 16, 3296-3313.

—, and — 2005: Atlantic Ocean forcing of North American and European summer climate. Science, 309, 115-118.

— port. [Available online at http://ugamp.nerc.ac.uk/predicate/.]

Timmermann, A., M. Latif, R. Voss, and A. Grötzner, 1998: Northern Hemisphere interdecadal variability: A coupled air-sea mode. J. Climate, 11, 1906-1931.

Vellinga, M., and R. A. Wood, 2002: Global climatic impacts of a collapse of the Atlantic thermohaline circulation. Climatic Change, 54, 251-267.

Visbeck, M., H. Cullen, G. Krahmann, and N. Naik, 1998: An ocean model's response to North Atlantic Oscillation-like wind forcing. Geophys. Res. Lett., 25, 4521-4524. 